\title{
A Study on the Prevalence of Depression among Young Adults in South India
}

\author{
R. Dhanasekara Pandian ${ }^{1}$, Sreeranjini T², Agnieta Aiman ${ }^{3}$, Soyuz John ${ }^{4}$, Shishir ${ }^{5}$, \\ Santhosh Prabhu ${ }^{6}$, Shrinivasa Bhat $U^{7}$, Anish V. Cherian ${ }^{8}$
}
${ }^{1}$ Additional Professor, Department of Psychiatric Social Work, National Institute of Mental Health and Neurosciences (NIMHANS), Bangalore, India- 560029
${ }^{2}$ MBBS student, K. S. Hegde Medical Academy, Deralakkatte, Mangalore
${ }^{3}$ Lecturer/Psychiatric Social Worker, Department of Psychiatry, K. S. Hegde Medical Academy, Deralakkatte, Mangalore
${ }^{4}$ Ph.D Scholar, Department of Psychiatric Social Work, National Institute of Mental Health and Neurosciences (NIMHANS), Bangalore, India- 560029
${ }^{5}$ Assistant professor of Psychiatry, K. S. Hegde Medical Academy, Deralakkatte, Mangalore
${ }^{6}$ Assistant professor of Psychiatry, K. S. Hegde Medical Academy, Deralakkatte, Mangalore
${ }^{7}$ Professor of Psychiatry, K. S. Hegde Medical Academy, Deralakkatte, Mangalore
${ }^{8}$ Additional Professor, Department of Psychiatric Social Work, National Institute of Mental Health and Neurosciences (NIMHANS), Bangalore, India- 560029
E-mail-soyuzjohn@gmail.com

\begin{abstract}
Background: The study was aimed at finding out the prevalence of depressive symptoms among young adults in Karnataka.

Methodology: The study was a college based cross sectional survey. Socio demographic data sheet and Patient Health Questionnaire (PHQ-9) was administered 1500 college students aged between 18-30 years of age. The study carried out in the medical, dental, paramedical, engineering and other degree college students among colleges in Mangalore, Karnataka.

Results: majority of the respondents were females, day scholars, Hindus and came from nuclear families. $34.4 \%$ felt minimal depression, $38.0 \%$ felt mild depression, 13 . $2 \%$ had moderate depression, $4.5 \%$ had moderate to severe depression and $1.7 \%$ had severe depression.

Conclusions: The common mental disorder of depression is common among young adults. Awareness creation for parents and teachers can help them to identify, support and refer adults with depression to appropriate professionals. Teachers delivered, peer-delivered and professional delivered School based mental health programme and crisis management help line are few ways to deal with depression among the young adults.
\end{abstract}

Key words: Prevalence, Depression, Young adults.

(Paper received $-1^{\text {st }}$ April 2016, Peer review completed -12 th $^{\text {th }}$ April 2016, Accepted $-17^{\text {th }}$ April 2016)

\section{INTRODUCTION}

Depression is a common psychiatric condition that negatively affects feeling, thinking and acting. Depression causes feelings of sadness and/or a loss of interest in activities once enjoyed. Depression can lead to a multiple emotional and physical problems and can decrease a person's ability to function at work and at home [1]. The young people in the age group of 10-24 are characterized by immense growth and development. It is a stage of vulnerability often influenced by several risk and protective factors that affect 
their health and safety [2]. A study from Kerala among adolescents reported that $11.2 \%$ of school dropouts had severe and extreme grades of depression as against $3 \%$ among school going adolescents [3]. Another study from Noida Uttar Pradesh showed 38\% of adolescents had depression [4]. A psychiatric morbidity study among school adolescents in Tamil Nadu found that about $29 \%$ of girls and $23 \%$ of boys had depression [5]. Another school based study among adolescents from Tamil Nadu reported that $37.1 \%$ were mildly depressed, 19.4\% were moderately depressed and $414.3 \%$ severely depressed [6].

Feeling lonely ethnicity, using drugs, being bullied and lack of parental supervision were highly correlated with depression among adolescents [7]. Higher levels of depression were found to be related to more external locus of control and a tendency to attribute outcomes to causes which are internal, stable, and global [8]. Socio-demographics, life events, sexual abuse, physical abuse, and exposure to violence were found to be associated with depression among adolescents [9]. Engagement in sexual activity, parental monitoring of adolescent activity and paternal affection and support were related with adolescent depression [10].

Depression during adolescence is associated with academic difficulties, risky behavior engagement, nonsuicidal self-injury in later in adolescence and lower income levels, higher divorce rates, suicidality in adulthood [11-13]. More distressingly, $75 \%$ of individuals undergoing depression during adolescence will make a suicide attempt in adulthood [14]. So the objective of the current study was to assess the prevalence of depression among young adults.

\section{METHODOLOGY}

Study population: The present study was a cross sectional survey carried out in the medical, dental, paramedical, engineering and other degree college students among colleges in Mangalore, Karnataka. Young adults aged 18 - 30 years and registered in the colleges, participated in the study. Based on the findings from previous studies from similar setting and power calculations for primary outcomes, 1500 young adults were recruited for the study. Inclusion criteria for the study were; a) students between the age group of 18 and 30 years of age, b) students who were willing to take part in the study by signing an informed consent after listening to the study process and the students below the age of 18 and above the age of 30 are excluded from the study.

Tools of data collection: Self-rated semi-structured questionnaire to collect information on potential factors that influence depression like age, gender, marital status, education status and employment status was used for the study.

In addition, the Patient Health Questionnaire (PHQ-9) was used to assess the level of depression among the respondents. The PHQ-9 is a nine items tool covering DSM-IV criteria for Depression such as anhedonia, depressed mood, trouble sleeping, feeling tired, change in appetite, guilt, self-blame, or worthlessness, trouble concentrating, feeling slowed down or restless and thoughts of being better off dead or hurting oneself [15]. Each item is rated on a 4-point scale from 0 to 3 (0-never, 1 - several days, 2 more than half the time, and 3 - nearly every day) during the two weeks prior to and including the day of survey completion. The overall scores ranged from 0 to 27 . The cutoff score is 9 . The PHQ-9 had a sensitivity of $88 \%$ and a specificity of $88 \%$ for detecting depression [15].

Study procedures: After obtaining ethical approval from Institutional Review Board, K. S. Hegde Medical Academy, Mangalore, the researchers approached various colleges to seek permission to conduct study among students and invited them to participate in the study. After obtaining consent, the researcher distributed the self-rated semi-structured demographic questionnaire and the Patient Health Questionnaire (PHQ-9). The data was analyzed using the Statistical Package for Social Sciences (SPSS) version 16.0.

The Institutional Review Board (IRB) of K. S. Hegde Medical Academy, Mangalore gave ethical clearance to the protocol. Witnessed written informed consent was taken from all participating subjects. Participants were informed (A) about their right to withdraw consent at any stage and to refuse to answer any question (B) that data collected would be anonymized and could be used by other researchers beyond 
the term and scope of the current study. To ensure confidentiality, the researchers had assigned unique codes to each participant which was maintained throughout the study period. All identifying information was stored separately from the interview data. Those requiring advanced medical care were referred to the Department of Psychiatry, K. S. Hegde Medical Academy, Mangalore.

\section{RESULTS}

Table 1 - Demographic Details of the respondents

\begin{tabular}{|cc|}
\hline Variable & Mean ( S.D.) / N (\%) \\
\hline Age & $19.67(1.421)$ \\
\hline Female & $1340(89.3)$ \\
\hline Religion & $941(62.7)$ \\
Hindu & $283(18.9)$ \\
Muslim & $245(16.3)$ \\
Christian & \\
Stream & $321(21.4)$ \\
Medical and Allied health science & $346(23.1)$ \\
Humanities and Science & $1499(55.4)$ \\
Management and commerce & $1041(69.7)$ \\
\hline Residence & $358(23.9)$ \\
Home & $83(5.5)$ \\
Hostel & $11(0.7)$ \\
\hline Staying with, Relatives, Friends, Paying & \\
guest & $1182(78.7)$ \\
Staying alone & $212(14.1)$ \\
\hline Family type & \\
Nuclear & Joint \\
\hline
\end{tabular}

In the current study majority of the respondents $(89.3 \%)$ were female, mean age of the young adult was $19.67(\mathrm{SD} \pm 1.421)$ and most of them (62.7\%) were Hindus. Majority of the students (69.7\%) were day scholars and $23.9 \%$ of them were hostellers. Among the college students $78.7 \%$ were from nuclear family and $14.1 \%$ were from joint families.

Table 2 depicts the responses of the young adults in the different items of the PHQ. Majority of the respondents (45.4\%) felt 'little interest or pleasure doing things several days' and $8.9 \%$ felt 'no interest doing things nearly every day' for the last two weeks. Among the students, $50.5 \%$ felt 'not at all feeling depressed' and $9.5 \%$ and $6.2 \%$ felt 'depressed more than half of the day' and 'almost every day' for the last two weeks. Responding to sleep related question, $12.8 \%$ had sleep related problems 'almost every day'. Among the respondents $14.1 \%$ felt tired 'more than half of the day' and $9.1 \%$ felt low energy 'almost every day' while $7.3 \%$ had problems (poor eating or over eating) with eating 'almost every day' for the last two weeks. In the study $7.3 \%$ felt badly about themselves more than half of the day and $5.6 \%$ had the same feeling 'almost every day' for the last two weeks. Similarly, 4.1\% had concentration problems 'almost every day' and $3.5 \%$ had death wishes 'almost every day' for the last two weeks.

Table 3 illustrates the level of depression among the respondents. In the study, only $8.1 \%$ not felt any depression at all. Otherwise, 34.4\% felt minimal depression, 38.0\% felt mild depression, 13. 2\% had moderate depression, $4.5 \%$ had moderate to severe depression and $1.7 \%$ had severe depression.

\section{DISCUSSION}

The current cross sectional study on depression among young adult aged between 18-30 years of age was carried out among 1500 college students in Mangalore Karnataka. The mean age of the sample was 19.67 
(SD \pm 1.421$)$, most of them (89.3\%) were female and $62.7 \%$ were Hindus and $78.7 \%$ were from nuclear families. A study conducted among college going students on depression reported that mean age was 19.4 $(\mathrm{SD} \pm 1.2)$ years and $70.2 \%$ were females [16]. An Indian study reported that mean age of the sample was $20.84(\mathrm{SD} \pm 1.6$ ) years, $40.5 \%$ were male and $59.5 \%$ were female, $57 \%$ were Hindus and $77.5 \%$ were from nuclear families [10].

Table 2 - Patient Health Questionnaire (PHQ) item-wise finding

\begin{tabular}{|c|c|c|c|c|c|}
\hline No & PHQ & $\begin{array}{c}\text { Not at all } \\
\text { Mean( S.D) }\end{array}$ & $\begin{array}{l}\text { Several days } \\
\text { Mean } \\
\text { (S.D) }\end{array}$ & $\begin{array}{l}\text { More than } \\
\text { half the day } \\
\text { Mean } \\
\text { (S.D) }\end{array}$ & $\begin{array}{c}\text { Nearly every } \\
\text { day } \\
\text { Mean } \\
\text { (S.D) }\end{array}$ \\
\hline 1. & $\begin{array}{c}\text { Little interest or pleasure in doing } \\
\text { things }\end{array}$ & $464(30.9)$ & $681(45.4)$ & $222(14.8)$ & $134(8.9)$ \\
\hline 2. & $\begin{array}{c}\text { Feeling down depressed or } \\
\text { hopeless }\end{array}$ & $758(50.5)$ & $507(33.8)$ & $143(9.5)$ & $93(6.2)$ \\
\hline 3. & $\begin{array}{l}\text { Trouble falling or staying asleep or } \\
\text { sleeping too much }\end{array}$ & $620(41.3)$ & $491(32.7)$ & $197(13.1)$ & $192(12.8)$ \\
\hline 4. & Feeling tired or having little energy & $491(32.7)$ & $662(44.1)$ & $212(14.1)$ & $136(9.1)$ \\
\hline 5. & Poor appetite or over eating & $838(55.8)$ & $413(27.5)$ & $141(9.4)$ & $109(7.3)$ \\
\hline 6. & $\begin{array}{c}\text { Feeling bad about yourself-or that } \\
\text { you are a failure or have let } \\
\text { yourself or your family down }\end{array}$ & $940(62.6)$ & $367(24.5)$ & $110(7.3)$ & $84(5.6)$ \\
\hline 7. & $\begin{array}{l}\text { Trouble concentrating on things, } \\
\text { such as reading the newspaper or } \\
\text { watching television }\end{array}$ & $955(63.6)$ & $394(26.2)$ & $90(6.0)$ & $62(4.1)$ \\
\hline 8. & $\begin{array}{l}\text { Moving or speaking so slowly that } \\
\text { other people could have noticed? } \\
\text { Or the opposite being so fidgety or } \\
\text { restless that you have been moving } \\
\text { around a lot more than usual }\end{array}$ & $1116(74.4)$ & $278(18.5)$ & $62(4.1)$ & $45(3.0)$ \\
\hline 9. & $\begin{array}{c}\text { Thoughts that you would be better } \\
\text { off dead or of hurting yourself in } \\
\text { the some way }\end{array}$ & $1220(81.3)$ & $184(12.3)$ & $44(2.9)$ & $53(3.5)$ \\
\hline
\end{tabular}

Table 3 - Level of depression of the respondents

\begin{tabular}{|c|c|}
\hline Variables (PHQ) & Mean ( S.D) / N ( \%) \\
\hline Not at all & $122(8.1)$ \\
\hline Minimal depression & $516(34.4)$ \\
\hline Mild depression & $571(38.0)$ \\
\hline Moderate depression & $198(13.2)$ \\
\hline Moderately severe depression & $68(4.5)$ \\
\hline Severe depression & $26(1.7)$ \\
\hline
\end{tabular}


The sample size of the current study was 1500 young adults aged between 18-30 years of age. 800 students studying in class IX to class XII participated in a study from Uttar Pradesh [4]. 338 school going children participated in another study [3], 964 school going adolescents participated a study from Tamil Nadu [6]. The present study findings were very significant because prevalence rate of depression among the population was alarmingly high. In the study $34.4 \%$ felt minimal depression, $38.0 \%$ felt mild depression, $13.2 \%$ had moderate depression, $4.5 \%$ had moderate to severe depression and $1.7 \%$ had severe depression. Another study from Tamil Nadu stated that 9.3\% were minimally depressed, $25.4 \%$ were mildly depressed, $45.7 \%$ were modernly depressed and 19.6\% severely depressed [5]. In another study, the overall prevalence of depression among students was 38\%. Majority of subjects $(75.7 \%)$ were having mild depression followed by moderate depression (23.5\%). Only 1 study subject was found to have moderately severe depression [4]. Prevalence of severe and extreme depression among adolescents was 9.5\% [3]. Another study from India on depression among adolescents reported that $39.2 \%$ presented with 'no depression'. Mild depression was found in 37.1\% adolescents. The number of adolescents who reported moderate depression was $19.4 \%$ and severe depression was $4.3 \%$ [6].

The Patient Health Questionnaire (PHQ-9) with nine items was found to be very effective and useful tool to assess level of depression among young adults. There were many studies used the same tool to assess depression among adolescents. The same tool was used to assess depression among in-school adolescents in Nigeria [17]. Two other studies from India also utilized the same scale to assess the level of depression among adolescents [4,10]. Another tool which was often preferred by researchers to assess level of depression among adolescents is Beck Depression Inventory (BDI). There were number of studies with $\mathrm{BDI}$ as a tool to assess depression [3,6,16,18-20].

\section{CONCLUSIONS}

The depression and suicidal thoughts are common among young adults in Mangalore, Karnataka. These findings are corroborative and go in hand with many other study findings from across the country. Creating a supportive environment both in college and at home will help the young adults to express their feelings. Various crisis support networks such as crisis phone help line, online support systems, peer discussions, one to one counseling and consultation can be recommended for the support of the students. Finally, it is recommended that, in the study area, the current national policies and programs for young adults should prioritize the suicide prevention and tackling depression among young adults.

\section{REFERENCES}

1. Oquendo MA. APA's Methodical Approach to Communication. Psychiatr News. 2017;52(5):1-1.

2. Sunitha S, Gururaj G. Health behaviours \&amp; problems among young people in India: cause for concern and amplification; call for action. Indian J Med Res 2014;140(2):185-208.

3. Nair MKC, Paul MK, John R. Prevalence of depression among adolescents. Indian J Pediatr 2004;71(6):523-4.

4. Chauhan S, Lal P, Nayak H. Prevalence of Depression among School Children aged 15 years and above in a Public School in Noida, Uttar Pradesh. J Acad Ind Res 2014;3(6):269-273.

5. Jayanthi $P$, Thirunavukarasu M. Prevalence of depression among school going adolescents in south India. Int J Pharm Clin Res 2015;7(1):61-3.

6. Rani Mohanraj KS. Prevalence of depressive symptoms among urban adoloscents in South India. J Indian Assoc Child Adoloscent Mental Health 2010;6(2):33-43.

7. Kaur J, Cheong SM, Mahadir Naidu B, Kaur G, Manickam MA, Mat Noor M, Ibrahim N, Rosman A. Prevalence and Correlates of Depression Among Adolescents in Malaysia. Asia Pacific J Public Health. 2014;26(5):S53-62.

8. Siegel LJ, Griffin NJ. Correlates of depressive symptoms in adolescents. J Youth Adolesc 1984;13(6):475-87.

9. Glied S, Pine DS. Consequences and Correlates of Adolescent Depression. Arch Pediatr Adolesc Med 2002;156(10):1009-14.

10. Kaur S, Deepti SS, Lal M. Prevalence and Correlates of Depression among College going students of District Amritsar, India. Int Res J Med Sci. 2014;2(11):5-9. 
11. Auerbach RP, Kim JC, Chango JM, Spiro WJ, Cha C, Gold J, Esterman M, Nock MK. Adolescent nonsuicidal self-injury: examining the role of child abuse, comorbidity, and disinhibition. Psychiatry Res 2014;220(1-2):579-84.

12. Auerbach RP, Eberhart NK, Abela JRZ. Cognitive vulnerability to depression in Canadian and Chinese adolescents. J Abnorm Child Psychol 2010;38(1):57-68.

13. Avenevoli S, Swendsen J, He JP, Burstein M, Merikangas KR. Major depression in the national comorbidity survey-adolescent supplement: prevalence, correlates, and treatment. J Am Acad Child Adolesc Psychiatry 2015;54(1):37-44.

14. Nock MK, Green JG, Hwang I, McLaughlin KA, Sampson NA, Zaslavsky AM, Kessler RC. Prevalence, correlates, and treatment of lifetime suicidal behavior among adolescents. JAMA Psychiatry. 2013;70(3):30010 .

15. Kroenke K, Spitzer RL, Williams JBW. The PHQ-9: Validity of a brief depression severity measure. J Gen Intern Med 2001;16(9):606-13.

16. Uglesic B, Lasic D, Zuljan-Cvitanovic M, Bukovic D, Karelovic D, Delic-Brkljacic D, Bukovic N, Radan M. Prevalence of depressive symptoms among college students and the influence of sport activity. Coll Antropol 2014;38(1):235-9.

17. Fatiregun AA, Kumapayi TE. Prevalence and correlates of depressive symptoms among in-school adolescents in a rural district in southwest Nigeria. J Adolesc 2014;37(2):197-203.

18. Park SC, Kim D, Jang EY. Prevalence and symptomatic correlates of interpersonal trauma in South Korean outpatients with major depressive disorder. Compr Psychiatry 2016;66:46-52.

19. Barroilhet S, Fritsch R, Guajardo V, Martinez V, Vohringer P, Araya R, Rojas G. Suicidal ideation, selfdirected violence and depression among Chilean school adolescents. Rev Med Chil 2012;140(7):873-81.

20. Chen L, Wang L, Qiu XH, Yang XX, Qiao ZX, Yang YJ, Liang Y. Depression among Chinese university students: prevalence and socio-demographic correlates. PLoS One 2013;8(3):1-6.

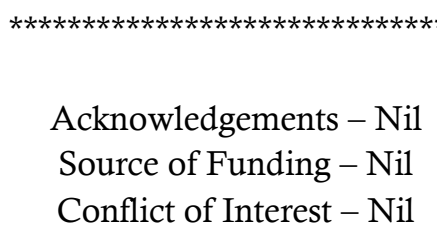

